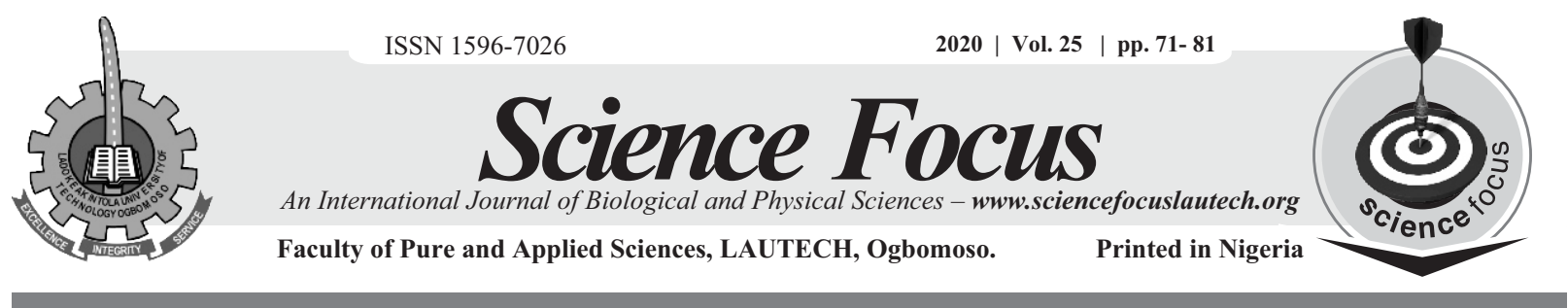

https://doi.org/10.36293/sfj.2020.0052

\title{
SURFACE SCREENING OF ZEA MAYS BAGASSE ADSORBENT AND APPLICATION FOR REMOVAL OF AQUEOUS MALACHITE GREEN OXALATE FROM WASTE WATERS
}

\author{
ADENIKE MADINAT ADEGBOYEGA ${ }^{1}$, ADEOLA YEWANDE BAMIGBOYE ${ }^{\mathbf{1}}$, \\ TEMITOPE DORCAS AKIN-IBITAYO ${ }^{1}$, GABRIEL AYOTUNDE OLORUNNIYI ${ }^{2}$, \\ TEMITOPE CHRIS ALAGBADA ${ }^{3}$, SAMUEL ADEWALE ADEGBOYEGA ${ }^{3}$ * * \\ ${ }^{1}$ Department of Chemistry, The Polytechnic, Ibadan, Ibadan, Oyo State, Nigeria \\ ${ }^{2}$ Department of Chemistry, University of Ibadan, Ibadan, Nigeria. \\ ${ }^{3}$ Department of Pure and Applied Chemistry, Ladoke Akintola University of Technology, Ogbomoso,
}

Nigeria

\begin{abstract}
The sorption of Malachite green dye Oxalate (MG Oxalate) from aqueous media was investigated using the batch adsorption process. Effects of contact time, biosorbent dose, initial concentration, temperature, and solution $p H$ were assessed. Certain physicochemical and spectroscopic descriptions of the sorbent were carried out such as proximate, bulk density, iodine size particle, $p H_{P Z C}$ (point of zero charge), Scanning Electron Microscopy (SEM), Energy dispersive X-ray spectroscopy (EDS), and Fourier Transformed Infrared Spectroscopy (FTIR). Pseudo first order, pseudo-second-order kinetics, and Langmuir, Freundlich Isotherms were engaged to investigate the mechanism and nature of the sorption. The proximate composition reveals that Zea mays bagasse contains a high carbohydrate content of 78.37 $\%$, and this was established by elemental analysis using EDS which disclose that the percentage of carbon atom in the material was $83.45 \%$. The bulk density, the area of the surface, and the size particle of the Zea mays bagasse were $0.119 \mathrm{~g} \mathrm{~cm}^{-3}, 42.2 \mathrm{~m}^{2} \mathrm{~g}^{-1}$ and $250 \mu \mathrm{m}$ respectively. The SEM micrograph shows that the size of the pores of the Zea mays bagasse ranges between $75-100 \mu \mathrm{m}$. FTIR revealed the following functional groups on the adsorbent: $\mathrm{O}-\mathrm{H}$ stretch (free), $\mathrm{N}-\mathrm{H}$ stretch, $\mathrm{C}-\mathrm{H}$ stretch, $\mathrm{C}=\mathrm{O}$ stretch aldehyde among others. Adsorption Kinetics and isothermal studies revealed that the pseudo-secondorder kinetic model and Freundlich adsorption isotherms best described the sorption process between Zea mays bagasse and $M G$ oxalate. The thermodynamic parameters, $\Delta G, \Delta H$, and $\Delta S$, disclosed that Gibb's free energy change (negative) depicts a possible and spontaneous process. The change in enthalpy was an endothermic process likewise the positive entropy infers randomness at the solid/solution interface of the sorbent all through the process of adsorption. Zea maize bagasse is a potential sorbent for the uptake of MG oxalate with sufficient surface properties which aid the sorption process of the adsorbate on the adsorbent
\end{abstract}

Keywords: Surface, adsorption, Zea mays, MG oxalate, Kinetics, thermodynamics

Corresponding Author Email: samueladegboyega45@gmail.com, saadegboyega92@lautech.edu.ng 


\section{Introduction}

Wastewater from textile and dyestuff industries is one of the most challenging industrial wastewater to treat (Kaushik and Malik 2009). Dyestuff, textiles, paper, and plastics industries to mention few utilized dyes for their products' coloration and the volume of water they consume is large. These industries release dyes in large amounts in form of affluent polluting the aquatic environment because of their dyeing activities. About 280,000 tons of textile dyes are released annually in form of industrial run-offs globally (Maas and Chaudhari 2005). As a result, they produce a substantial quantity of colored wastewater. The first pollutant to be acknowledged in wastewater is color (Banat et al. 1997). The occurrence of dyes in a very lesser amount in water $(<1 \mathrm{mg} / \mathrm{L}$ for certain dyes) is extremely obvious and undesirable (Robinson et al. 2001). The toxic effects of dyes on humans are direct and indirect which are accompanied by mutations, heart defects, skin irritation, tumors, jaundice, and cancer (Alver and Metin 2012).

Malachite green oxalate is a cationic dye with IUPAC name Bis[[4-[4(dimethylamino)benzhydrylidene]cyclohexa -2,5-dien-1-ylidene]dimethylammonium] dioxalate oxalate, it is an organic compounds with molecular formula, $\mathrm{C}_{23} \mathrm{H}_{25} \mathrm{~N}_{2} \mathrm{C}_{2} \mathrm{HO}_{4}$ $0.5 \mathrm{C}_{2} \mathrm{H}_{2} \mathrm{O}_{4}$; molar mass $463.50 \mathrm{gmol}^{-1}$ ). Malachite green is utilized traditionally as a dye for substances like leather, paper, and silk. Various chemical, physical and biological methods of treatment (for instance coagulation ion-exchange, adsorption, flocculation, reverse osmosis, electrochemical, chemical oxidation, ozonation, and biodegradation techniques) have been utilized for the uptake of dye molecules from wastewater ( Crini, 2006; Blackburn, 2004). Nevertheless, these methods recorded many setbacks ranging from their efficiency to availability (Garg et al. 2003).
Agricultural wastes are broadly obtainable, inexpensive, and contain a large amount of surface functional groups which make agricultural wastes good substitutes to costly synthetic adsorbents (Amarasinghe and Williams, 2007). Zea mays bagasse is a waste material from maize plant with the potential surface structure which could enhance the uptake of malachite green oxalate from aqueous media. The search for more efficient, effective, and cheap novel adsorbents are the urgent focus of this research which investigates the Zea mays bagasse for scavenging of malachite green Oxalate from aqueous media.

\section{Materials and Method}

\section{Preparation of Zea mays bagasse (biosorbent)}

The biosorbent, Zea mays bagasse used in this research, was collected from The Polytechnic of Ibadan quarters, Nigeria. It was peeled and washed twice with de-ionized water, then air dried for two days and thereafter oven-dried at $105{ }^{\circ} \mathrm{C}$ for $22 \mathrm{~h}$. The bagasse undergoes pulverization at the department of Agronomy, University of Ibadan, the pulverized bagasse was then sieved (sieved to particle sizes between 250 $\mu \mathrm{m}$ and $425 \mu \mathrm{m})$ and was stored in an airtight container.

\section{Characterization of Zea mays bagasse}

\section{Surface area}

Specific area of the surface of the pulverized biosorbent was ascertained according to Sears, (1956). In this method, $1.5 \mathrm{~g}$ sample weight was acidified using $0.1 \mathrm{M} \mathrm{HCl}$ to $\mathrm{pH}$ between $3-$ 3.5. Deionized water was added to top-up the volume to $50 \mathrm{~mL}$ after adding $10.0 \mathrm{~g}$ of $\mathrm{NaCl}$. The titration was performed with standard $0.1 \mathrm{M}$ $\mathrm{NaOH}$, to $\mathrm{pH} 4.0$, and later to $\mathrm{pH} 9.0$ at $25^{\circ} \mathrm{C}$ in a thermostatic bath. The required volume (v), to increase the $\mathrm{pH}$ from 4.0 to 9.0 was documented and the area of the surface was calculated via the expression below:

$S\left(\frac{m^{2}}{g}\right)=32 V-25$ 


\section{Bulk density}

A density bottle of $25 \mathrm{~cm}^{3}$ was utilized to determine the bulk density of the adsorbent. The density bottle was filled with the biosorbent and it was ensured that all air spaces were occupied. The weight of the density bottle comprising the biosorbent was estimated. The biosorbent weight that filled $25 \mathrm{~cm}^{3}$ was gotten from the bottle weight and this is the bottle weight plus biosorbent minus the weight of empty bottle only, this was used to obtained the density of the adsorbent (Ofomaja and Naidoo 2011).

\section{pH point of zero charge}

The $\mathrm{pH}$ of point of zero charge $\left(\mathrm{pH}_{\mathrm{pzc}}\right)$ of the biosorbent was estimated using the solid addition technique (Stumm and Morgan 1996) by adding $45 \mathrm{~mL} 0.01 \mathrm{~mol} \mathrm{dm}^{-3}$ solution of $\mathrm{KNO}_{3}$ each to six different conical flasks. The $\mathrm{pH}$ values for the $\mathrm{KNO}_{3}$ solutions undergo alteration to desired $\mathrm{pH}_{\mathrm{i}}(2,4,6,8,10$, and 12) by adding $0.1 \mathrm{~mol} \mathrm{dm}^{-3} \mathrm{NaOH}$ or $\mathrm{HCl}$. The solution aggregate volume in the entire flask was made-up to $50 \mathrm{~mL}$ via $\mathrm{KNO}_{3}$ solution addition of equal strength. The addition of $0.1 \mathrm{~g}$ of biosorbent to the solution was carried out and was instantly capped firmly. The equilibration of the suspensions was permitted with intermittent manual shaking for $48 \mathrm{~h}$. After $48 \mathrm{~h}$, the solution $\mathrm{pH}$ values $\left(\mathrm{pH}_{\mathrm{f}}\right)$ were observed. The differences between initial and final $\mathrm{pH}$ values $\left(\Delta \mathrm{pH}=\mathrm{pH}_{\mathrm{i}}\right.$ $\left.\mathrm{pH}_{\mathrm{f}}\right)$ were plotted versus the $\mathrm{pH}_{\mathrm{f}}$ The intersection point of the resultant curve at which $\Delta \mathrm{pH}=0$ gave the $\mathrm{pH}_{\mathrm{pzc}}$ (Bello, Ahmad, and Semire 2015).

\section{Proximate analysis}

Proximate analysis was performed on the Zea mays bagasse in the Department of Human Nutrition, University of Ibadan, based on the techniques of Official Analytical Chemist (AOAC 1990).

\section{FT-IR analysis of the biomass}

The available functional groups in the unloaded biomass were detected via Fourier transform infrared (FTIR). Spectra of the biomass were acquired at $400-4000 \mathrm{~cm}^{-1}$ wavenumber range via a Perkin Elmer FT-IR spectrophotometer.

\section{Biosorption of malachite green}

\section{Effect of pH}

The $\mathrm{pH}$-dependent studies of malachite green were performed within the range that would not be influenced by precipitation. $100 \mathrm{mg}$ of the biomass was weighed into a $100 \mathrm{~mL}$ plastic container. $0.1 \mathrm{M} \mathrm{HCl}$ and/or $0.1 \mathrm{M} \mathrm{NaOH}$ were utilized in a drops to adjust the $\mathrm{pH}(2,4,6,8,10$, and 12) of the dye solutions and $50 \mathrm{~mL}$ of the solution at each adjusted $\mathrm{pH}$ were measured accurately into the $100 \mathrm{~mL}$ container containing the adsorbent. These were agitated in a temperature-regulated shaker for 180 minutes. Thereafter the adsorbent was alienated from the adsorbate by centrifugation for $15 \mathrm{~min}$ at 15000 $\mathrm{rpm}$. The residual supernatant dye concentration was then examined via UV/Vis Spectrophotometer at the maximum wavelength of absorption $(616.5 \mathrm{~nm})$.

\section{Effect of biomass dose on malachite green oxalate}

Various masses of the Zea mays bagasse ( $5 \mathrm{mg}$, $50 \mathrm{mg}, 250 \mathrm{mg}, 500 \mathrm{mg}$, and $1000 \mathrm{mg}$ ) of biomass were taken into a $100 \mathrm{~mL}$ plastic container having $50 \mathrm{~mL}$ of $100 \mathrm{mg} / \mathrm{L}$ dye solutions. The dye solution $\mathrm{pH}$ in each case was altered to the optimum $\mathrm{pH}$ by adding $0.1 \mathrm{M}$ $\mathrm{NaOH}$ and $0.1 \mathrm{M} \mathrm{HCl}$ in drops followed by agitation in a temperature-controlled shaker for 180 minutes. Centrifugation techniques were used for adsorbent-adsorbate separation. The supernatant dye concentration was then analyzed via UV/Vis Spectrophotometer.

\section{Effect of contact time on biosorption of malachite green}

The sorption study was carried out under different atmospheric conditions at various agitation time intervals $(1,5,10,15,30,45,60$, 120 , and 180 minutes). $25 \mathrm{~mL}$ of $100 \mathrm{mg} \mathrm{L}^{-1}$ of dye solutions were adjusted to their optimum $\mathrm{pH}$ and contacted with $50 \mathrm{mg}$ of the modified biomass. Agitation was done in a batch process using a thermostatic water bath shaker. The 
adsorbent was alienated from the adsorbate by centrifugation. The supernatant dye concentration was then analyzed using a UV/Vis Spectrophotometer.

\section{Effect of Concentration on biosorption of malachite green}

The biosorption experiment was carried out at various dye magnitude $(5,10,20,50$, and 100 $\mathrm{mg} / \mathrm{L}$ ). $50 \mathrm{mg}$ of the biosorbent (Zea mays bagasse) weighed up into $100 \mathrm{~mL}$ plastic containers having $25 \mathrm{~mL}$ dye solution of different concentration. The $\mathrm{pH}$ was altered to the optimum $\mathrm{pH}$ using $0.1 \mathrm{M} \mathrm{HCl} / \mathrm{NaOH}$. Agitation was done in a thermostatic water bath shaker at $25{ }^{\circ} \mathrm{C}, 45^{\circ} \mathrm{C}$, and $55^{\circ} \mathrm{C}$ temperatures for $120 \mathrm{~min}$. The concentration of supernatant dye of each was then evaluated via UV/Vis Spectrophotometer at maximum wavelength of absorption $(616.5 \mathrm{~nm})$. The magnitude of dye uptake per unit weight of Zea mays bagasse and the sorption capability at time $\mathrm{t}, \mathrm{q}_{\mathrm{t}}(\mathrm{mg} / \mathrm{g})$ in each case were estimated by the use of the weight balance equation 2 and 3 respectively (Zenasni, Jamison, and Lee 2013).

$$
\begin{aligned}
& q_{e}=\frac{\left(c_{0}-c_{e}\right) V}{W} \\
& q_{t}=\frac{\left(c_{0}-c_{0}\right) V}{W}
\end{aligned}
$$

\section{Adsorption isotherms}

These display the dependence of the magnitude of substance adsorbed from the solution on concentration at a constant temperature. The adsorbent sorption capacity is estimated utilizing the adsorption isotherm models. Langmuir and Freundlich isotherm models were the frequent isotherms utilized in the liquid phase for modeling the adsorption process (Repo 2011; Willis 2009). The data was modeled with linearized Freundlich and Langmuir isotherm models as in equation 4 and 5 respectively

$$
\ln q_{e}=\frac{1}{n} \ln C_{e}+\ln K_{f}
$$

$\frac{C_{e}}{q_{e}}=\frac{C_{Q}}{q_{m}}+\frac{1}{K_{L} q_{m}}$

\section{Thermodynamic parameters}

These parameters $\left(\Delta \mathrm{G}^{0}, \Delta \mathrm{H}^{0}\right.$, and $\left.\Delta \mathrm{S}^{0}\right)$ revealed the process spontaneity and feasibility, likewise the effect of temperature on the adsorption process. In general, the estimation of the thermodynamic parameter has been carried out using the van't Hoff expression (equation 6), and $\Delta \mathrm{G}$ was obtained using the mathematical relation in equation 7 (Pounds 2001).

$\ln k_{L}=\frac{\Delta S}{\mathrm{R}}-\frac{\Delta \mathrm{H}}{\mathrm{RT}}$

$\Delta G^{\circ}=-R T \ln K_{L}$

\section{Adsorption kinetics}

The sorption kinetics data were modeled with linearized pseudo-first-order and the pseudo second-order as stated in equations 8 and 9 respectively (Ho 2006).

$$
\ln \left(q_{e}-q_{t}\right)=\ln q_{e}-k_{1} t
$$

$\frac{t}{q_{t}}=\frac{1}{k_{2} q_{\mathrm{e}}^{\mathrm{a}}}+\frac{1}{q_{\mathrm{e}} t}$

In all these equations, the description of various parameters is given as follows:

$\mathrm{k}_{1}\left(\mathrm{~min}^{-1}\right)$ is the pseudo-first-order rate constant, $\mathrm{q}_{\mathrm{e}},(\mathrm{mg} / \mathrm{g})$ symbolizes equilibrium adsorption capacity, $C_{\mathrm{o}}(m g / L)$ and $\mathrm{V}(\mathrm{mL})$ are the initial concentration and volume of the adsorbate, $\mathrm{W}$ is the mass of the adsorbent in $\mathrm{mg}$., $\mathrm{q}_{\mathrm{t}}(\mathrm{mg} / \mathrm{g})$ is the sorption capacity at time $\mathrm{t}, \mathrm{k}_{2}(\mathrm{~g} / \mathrm{mg} \mathrm{min})$, is the pseudo-second-order rate constant, $\mathrm{C}_{\mathrm{e}}$ is equilibrium concentration $(\mathrm{mg} / \mathrm{L}), \quad \mathrm{q}_{\mathrm{m}}$ is maximum sorption capacity $(\mathrm{mg} / \mathrm{g}), \mathrm{K}_{\mathrm{F}}$ is Freundlich affinity constant (based on $(\mathrm{mg} / \mathrm{g}) /$ $(m g / L)), \mathrm{K}_{\mathrm{L}}$ is the Langmuir's constant, $1 / \mathrm{n}$ is the heterogeneous factor, $\mathrm{T}$ is the temperature $(\mathrm{K}), \mathrm{K}_{\mathrm{L}}$ is the equilibrium constant as used in equation 7 and $\mathrm{R}$ is the universal gas constant $(8.314 \mathrm{~J} / \mathrm{mol} / \mathrm{K}) . \quad \Delta \mathrm{G}$ evokes the process spontaneity and feasibility, $\Delta \mathrm{H}$ described the enthalpy of reaction and likewise, the 
temperature effect on sorption and $\Delta \mathrm{S}$ imply the entropy of the process.

\section{Results and Discussion}

\section{Bulk density, particle size, and Surface area}

The bulk density, the surface area and the size particle of the Zea mays bagasse were $0.119 \mathrm{~g}$ $\mathrm{cm}^{-3}, 42.2 \mathrm{~m}^{2} \mathrm{~g}^{-1}$, and $250 \mu \mathrm{m}$ respectively.

\section{Proximate analysis}

The result from proximate analysis (Table 1) indicates that the adsorbent consists mainly of carbohydrates in the form of lignocellulose which is responsible for the basic adsorption properties of a particular adsorbent of organic origin.

\section{pH Point of zero charge}

The $\mathrm{pH}$ in which there is zero net charge on the adsorbent surface before adsorption is known as the $\mathrm{pH}$ of point of zero charge. The $\mathrm{pH}$ of the point of zero charge of Zea mays bagasse was estimated to be 7.098 as shown in Figure. 1, the biosorbent acquires a positive surface charge below the $\mathrm{pH}_{\mathrm{pzc}}$ in which the adsorption of anionic adsorbate is enhanced, whereas at the point above the $\mathrm{pH}_{\mathrm{pzc}}$, the biosorbent acquires a negative surface charge favouring the adsorption of cationic metal or dyes. The result from the point of zero charge revealed that the biosorption process between Zea mays bagasse adsorbent and Malachite green oxalate would better be optimized at $\mathrm{pH} 12$.

\section{FTIR spectra of Zea mays bagasse adsorbent}

The FTIR reveals that Zea mays bagasse adsorbent under study contains primarily the following functional peaks 3768.67, 3401.00, $2922.61,1726.20,1614.15,1375.54$, and $1250.48 \mathrm{~cm}^{-1}$ which was interpreted to contain the following functional groups $\mathrm{O}-\mathrm{H}$ stretch (free), $\mathrm{N}-\mathrm{H}$ stretch, $\mathrm{C}=\mathrm{O}$ stretch, $\mathrm{C}-\mathrm{H}$ stretch, aldehyde, N-H bend, C-H bending, and C-N stretch amine respectively. This shows that the adsorbent is capable of chemical interaction with the dye at the surface level.

\section{Scanning Electron Microscope (SEM)}

Figure 2 showed the scanning electron micrograph image resulting from the interaction of electron (from a thermionic electron gun source) with the sample which was therefore reflected as a secondary electron (from atoms of the sample that absorb the energy of electron beam) and was captured by the detector and displayed as a micrograph. The surface morphology of Zea mays bagasse adsorbent is in the order of $75 \mu \mathrm{m}-100 \mu \mathrm{m}$ with different magnifications which showed a porous surface with an irregular shape. This further justifies the suitability of the adsorbent for adsorption purposes.

\section{Energy dispersive X-ray spectroscopy (EDS)}

This shows the Elemental and chemical description of various atoms bound on the biosorbent surface. The sample was bombarded by the electron from Energy dispersive X-ray machine and the secondary electrons ejected from the sample were detected. The EDS x-ray measured the relative abundance of released $\mathrm{x}$ rays against their energy. The Zea mays bagasse contains $83.45 \% \mathrm{C}, 12.60 \% \mathrm{O}, 0.10 \% \mathrm{~S}, 2.31$ $\% \mathrm{Al}, 0.40 \% \mathrm{Mg}$, and $0.07 \% \mathrm{Cu}$ which is given in Figure 3. The effect of a particular adsorbent of organic origin would depend on carbonrelated functional compounds such as cellulose materials which serve as a good surface for adsorption to takes place.

\section{Adsorption Studies}

\section{Effect of pH}

The amount of electrostatic charges that are impacted by the ionized dye molecules is governed by the $\mathrm{pH}$ of the medium. Low $\mathrm{pH}$ is characterized to favours anionic dye and high $\mathrm{pH}$ favours cationic dyes, this respective $\mathrm{pH}$ range tends to influence the high dyes sorption capacity of adsoebents (Onal, Soyer, and Senkan 2006; Ozcan et al. 2007). Figure 4 divulge that the sorption capacity of Zea mays bagasse was $49.95 \mathrm{mg} / \mathrm{g}$ for MG Oxalate at $\mathrm{pH} 6$, and it was competitive with that obtained at $\mathrm{pH} 12$ with the value of $49.87 \mathrm{mg} / \mathrm{g}$. 


\section{Effect of increasing adsorbent dosage}

The plot of $\mathrm{q}_{\mathrm{e}}(\mathrm{mg} / \mathrm{g})$ against sorbent dosage $(\mathrm{mg})$ as displayed in Figure 5 indicates a reduction in the sorption capacity at equilibrium, $\mathrm{q}_{\mathrm{e}}$ as the sorbent dosage increases. This constant decrease has been attributed to the increases in the mass transfer resistance which is evident as adsorbent dose increases. The phenomenon results in the aggregation of particles of the adsorbent which in turn decreases the definite surface and diffusion path length increases. Omorogie et al., (2012) reported that the significant increase in aggregation relates directly to the rise in sorbent dosage.

\section{Effect of initial dye concentration and temperature increase}

Figure 6 represents the plot of the quantity of solute uptake at equilibrium $\mathrm{q}_{\mathrm{e}}(\mathrm{mg} / \mathrm{g})$ against the initial magnitude of the sorbate $C_{o}(\mathrm{mg} / \mathrm{L})$. The trend showed the rise in the adsorption capacity from 1.78 to $46.17 \mathrm{~m} \mathrm{mg}^{-1}$ as the initial concentration of the adsorbate increases from 5 to $100 \mathrm{mg} \mathrm{L}^{-1}$. Previous researches agreed that a rise in initial sorbate magnitude initiates a direct rise of the adsorbate molecules contending for the few existing active sites on the adsorbent, therefore for sorption of one molecule of dye, the active sites needed will be scarce (Kannan and Sundaram 2001; Ojedokun and Bello 2016). The adsorption capacity was realizably increasing with temperature increase, at the highest temperature of this work $(328 \mathrm{~K})$ the maximum adsorptive capacity was noticed to have increased from 46.17 to $98.35 \mathrm{mg} / \mathrm{g}$. Increasing temperature increases the mobility of dye molecules as well as affecting the existence of more active sites at a high temperature. A rise in sorption capacity with temperature is an indication that the adsorption process was endothermic (Senthilkumar et al. 2006; Nandi et al. 2009).

\section{Effect of contact time}

The importance of rate initial time as proposed by Azizian, (2006) was that the experiment should start at time, $\mathrm{t}<2 \mathrm{~min}$ (considered as initial time). At whichever time $t$, the concentration of adsorbate removal per weight of adsorbent $\mathrm{q}_{\mathrm{t}}$ approach that of equilibrium $\left(\mathrm{q}_{\mathrm{e}}\right)$ The plot as shown in Figure 7, is the graph of $\mathrm{q}_{\mathrm{t}}$ (mg/g) against Contact time (mins) which indicates a rapid increase in the adsorptive capacity $\mathrm{q}_{\mathrm{t}}$, from time, $\mathrm{t}<2 \mathrm{mins}(\mathrm{t}=1 \mathrm{~min})$ up to 30 mins where pore filling and other several interactions like electrostatic attraction, surface precipitation, $\pi-\pi$ interaction, hydrogen bonding, cation exchange, and $\mathrm{n}-\pi$ interaction was believed to be the adsorption mechanism for the porous adsorbent (Tran et al. 2017). After which equilibrium was reached at $120 \mathrm{mins}$, and at this point, the adsorption rate becomes slower.

\section{Adsorption kinetics}

These models aid the illustration of the whole sorption rate and its mechanism which was examined using kinetic expressions like pseudofirst-order PFO and pseudo-second-order PSO adsorptive modeling (Willis 2009). A plot of $1 n$ $\left(\mathrm{q}_{\mathrm{e}}-\mathrm{q}_{\mathrm{t}}\right)$ against $\mathrm{t}$ which is typical of pseudo-firstorder and a plot of $t / \mathrm{q}_{\mathrm{t}}$ against $\mathrm{t}$ with a slope of $1 / \mathrm{q}_{\mathrm{e}}$ and intercept $1 / \mathrm{k}_{2} \mathrm{q}_{\mathrm{e}}{ }^{2}$ for pseudo-secondorder model was used to obtain the adsorption kinetics parameters. Table 2 gives a distinctive sort out of adsorption kinetics parameters obtained from various plots above. The value of $\mathrm{R}^{2}$ (correlation coefficient), 0.94069 for the pseudo-first-order model was less than that which was obtained for the pseudo-second-order model, 0.99995. In contrast, the calculated adsorption capacity, $\mathrm{q}_{\mathrm{e}}(\mathrm{mg} / \mathrm{g})$ calculated showed that the pseudo-first-order model has an overriding adsorptive capacity, $\mathrm{q}_{\mathrm{e}}$ of 82.53 (mg/g) compared to the pseudo-second-order model which has an uptake of $50(\mathrm{mg} / \mathrm{g})$. Comparing the PFO and PSO rate constant $\mathrm{k}_{1}$ and $\mathrm{k}_{2}, \mathrm{k}_{2}=0.02<\mathrm{k}_{1}=0.069$ implies that MG Oxalate dye is composed of larger particle size. A small particle size yields a larger $\mathrm{k}_{2}$ value because of reduced intraparticle resistance (IPD) resistance (Babalola et al. 2016). A juxtaposition of the calculated value of adsorption capacity, $\mathrm{q}_{\mathrm{e}}=50(\mathrm{mg} / \mathrm{g})$ from PSO model with the experimental value $\mathrm{q}_{\mathrm{e}}=49.67(\mathrm{mg} / \mathrm{g})$ (i.e. $\mathrm{q}_{\mathrm{t}}=\mathrm{q}_{\mathrm{e}}$ at the time, $t \approx t$ ) showed the nearness of calculated $\mathrm{q}_{\mathrm{e}}$ value to that of the experimental value. This further validates the evidence that the mechanism of adsorption Kinetics for 
adsorption of MG Oxalate dye using Zea mays bagasse followed a pseudo-second-order kinetics model.

\section{Adsorption Isotherms}

Adsorption isotherms according to Repo, (2011); Willis, (2009), help in designing adsorption experimental system and to evaluate whether there is any deviation between experimental data and isotherm models, also to describe the nature of the adsorbent surface; investigating the type of adsorbate/adsorbent interactions whether monolayer or multilayer and the adsorption capacity of the sorbent. Table 3 summarizes the sorption equilibrium isotherms modeled with Langmuir and Freundlich isotherm model. The $\mathrm{R}^{2}$ values indicate that Freundlich isotherm $\left(\mathrm{R}^{2}=0.93649\right)$ at $318 \mathrm{~K}$ best described the sorption process. Langmuir isotherm doesn't fit at any temperature. 1/n values were obtained to describe the favourability of Freundlich isotherm in the adsorption process at that temperature. The Freundlich isotherm has adsorption capacity, $\mathrm{K}_{\mathrm{f}}$ $>b_{L}$, Langmuir adsorption capacity for the sorption

The thermodynamics parameters obtained at various temperatures $298 \mathrm{~K}, 318 \mathrm{~K}$, and $328 \mathrm{~K}$ were $-1.12715,-3.72062$, and $-6.56618 \mathrm{~kJ} / \mathrm{mol}$ respectively and these show that the adsorption was spontaneously feasible; the enthalpy of the adsorption process, $+50.37 \mathrm{~kJ} / \mathrm{mol}$ shows that the reaction was endothermic and the entropy, $+172.1746 \mathrm{~J} / \mathrm{mol} / \mathrm{K}$ discloses that the molecules of the adsorbate possess higher kinetic energy.

\section{Conclusion}

Zea mays bagasse consist of lingo-cellulose material with chemical functional groups which could enhance its chemical or physical interaction with the molecules, ions, or atoms of several adsorbates at the surface level. The adsorption process as described by Freundlich isotherm is a Physisorption (physical adsorption) with a heterogeneous surface, and involves the formation of multilayer molecules of adsorbate which involves weak intermolecular bonds and low adsorption energy. Pseudo-second order kinetics implication was that the sorption was chemisorptive. It might then be derived that the adsorption process between Zea mays bagasse and Malachite green oxalate is a mixture of chemical and physical sorption. The reaction was feasible and spontaneous.

\section{Conflict of interest}

The corresponding author states that there is no conflict of interest.

\section{Figures and Tables}

\section{Figures}

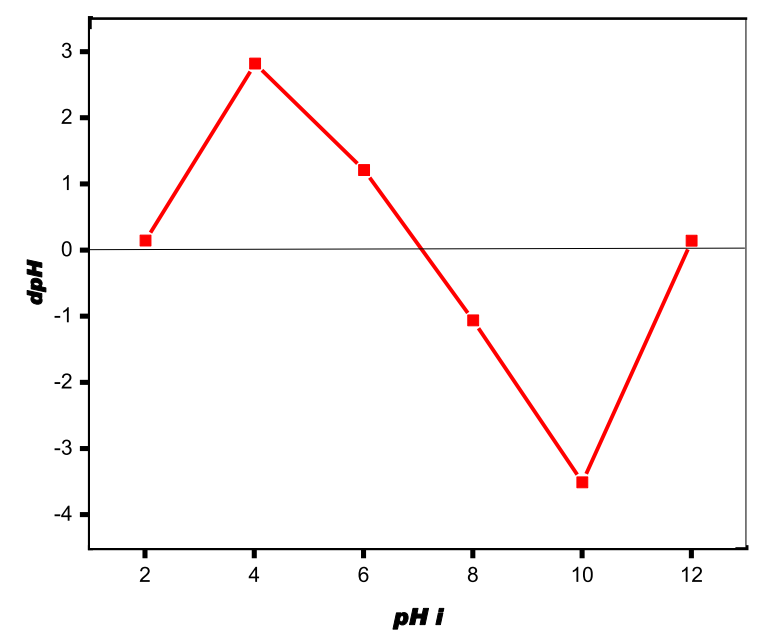

Figure 1: $\mathrm{pH}$ of point of zero charge 


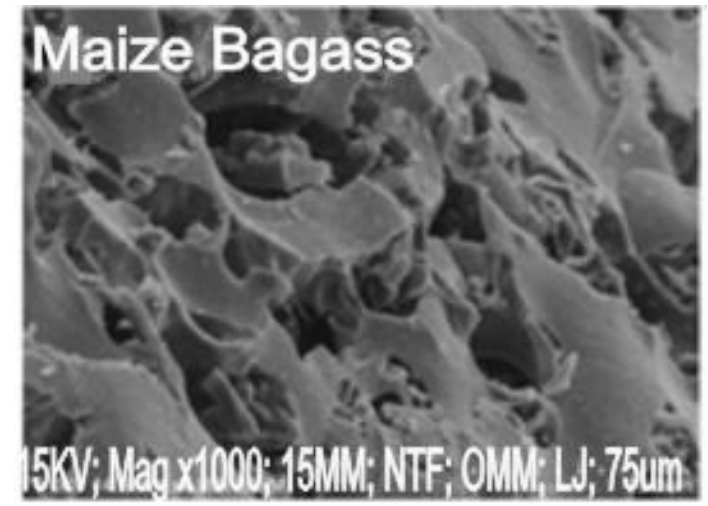

Figure 2: Scanning electron micrographs of Zea mays bagasse

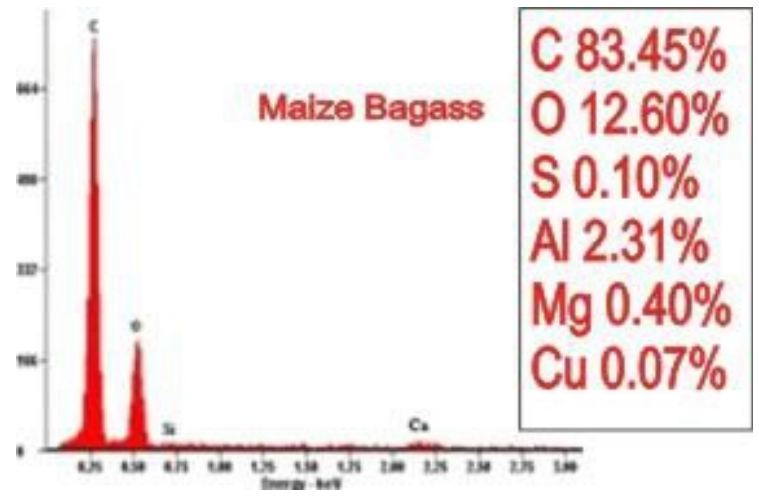

Figure 3: EDS spectrum of Zea mays bagasse

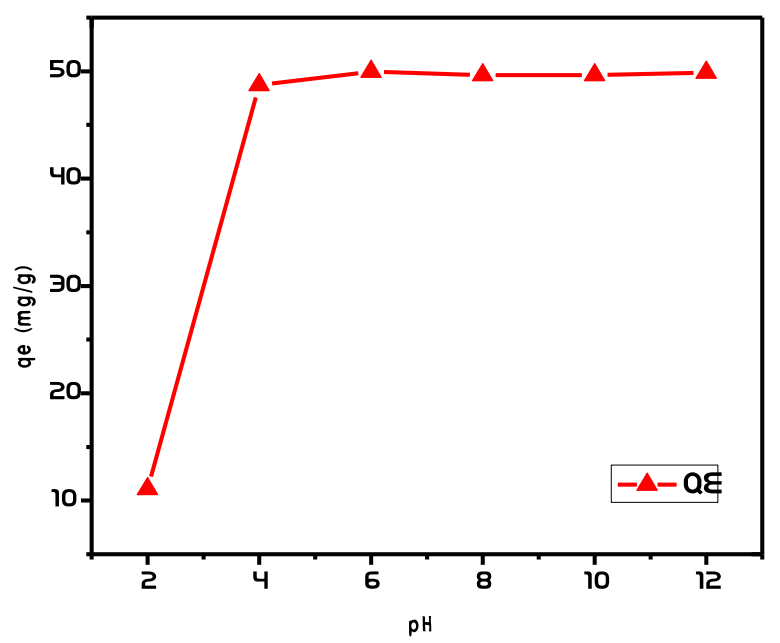

Figure 4: A graph of $\mathrm{q}_{\mathrm{e}}(\mathrm{mg} / \mathrm{g})$ versus $\mathrm{pH}$ for the sorption of $\mathrm{MG}$ oxalate unto Zea mays bagasse.

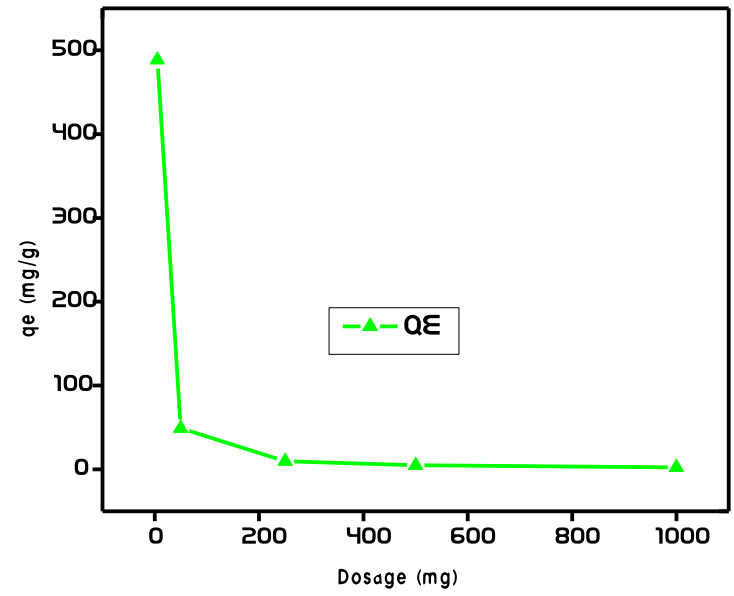

Figure 5: A graph of qe (mg/g) versus Dosage for the sorption of $\mathrm{MG}$ oxalate unto Zea mays bagasse.

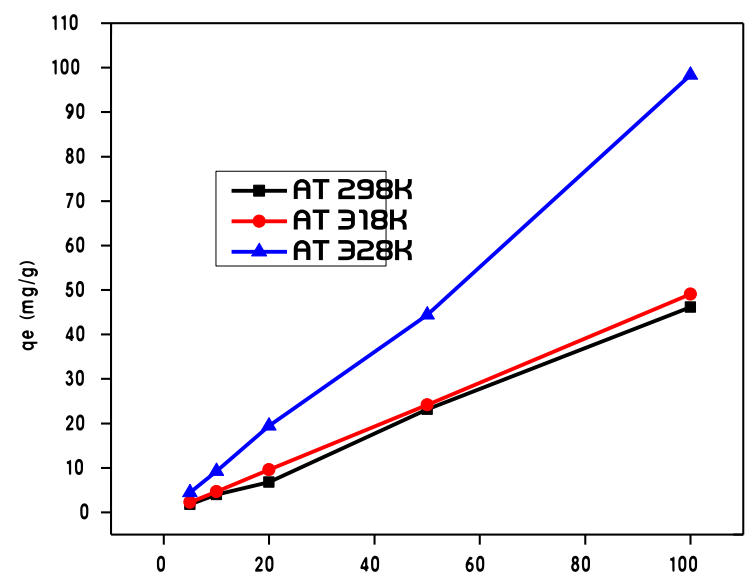

Figure 6: A graph shorwing the relationship between the initial concentration and $\mathrm{q}_{\mathrm{e}}(\mathrm{mg} / \mathrm{g})$ studies for the sorption of MG oxalate unto Zea mays bagasse.

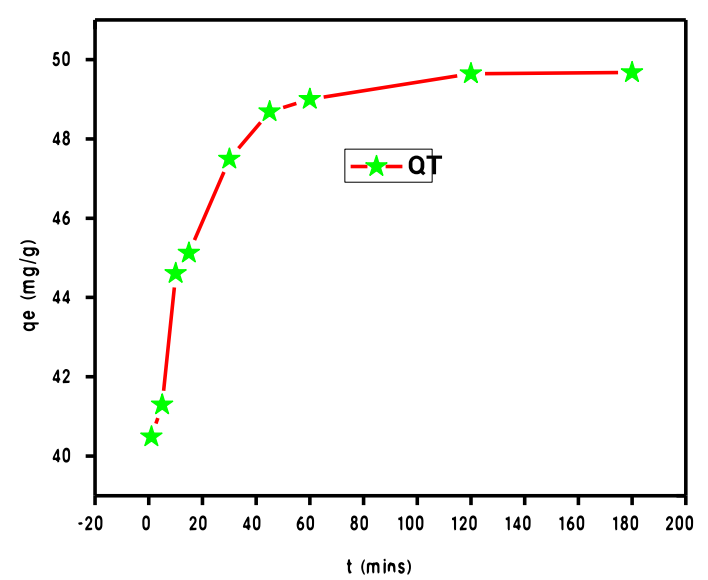

Figure 7: A graph showing kinetic studies for the sorption of $\mathrm{MG}$ oxalate unto Zea mays bagasse. 


\section{Tables}

Table 1: Proximate composition of Zea mays bagasse

\begin{tabular}{llllll}
\hline \% Moisture & \%Crude Protein & \% Crude Fat & Crude Fiber & \% Ash & \% CHO \\
\hline 10.42 & 5.69 & 0.82 & 40.40 & 4.70 & 37.97 \\
\hline
\end{tabular}

Table 2: Kinetic parameters for the sorption of MG oxalate unto Zea mays bagasse surface

\begin{tabular}{lll}
\hline Kinetic models & Parameters & Values \\
\hline & $\mathrm{K}_{1}\left(\mathrm{~min}^{-1}\right)$ & 0.069 \\
Pseudo-first order & $\mathrm{q}_{\mathrm{e}}\left(\mathrm{mg} \mathrm{g}^{-1}\right)$ & 82.53 \\
& $\mathrm{R}^{2}$ & 0.94069 \\
Pseudo-second order & $\mathrm{K}_{2}\left(\mathrm{~g} \mathrm{mg}^{-1} \min \right)$ & 0.02 \\
& $\mathrm{q}_{\mathrm{e}}\left(\mathrm{mg} \mathrm{g}^{-1}\right)$ & 50 \\
& $\mathrm{R}^{2}$ & 0.99995 \\
\hline
\end{tabular}

Table 3: Isotherm parameters for sorption of MG oxalate unto Zea mays bagasse Surface

\begin{tabular}{lllllll}
\hline \multicolumn{2}{c}{ Langmuir parameters } & \multicolumn{5}{c}{ Freundlich parameters } \\
\hline & $\begin{array}{l}\mathrm{q}_{\max } \\
\left(\mathrm{mg} \mathrm{g}^{-1}\right)\end{array}$ & $\begin{array}{l}\mathrm{b}_{\mathrm{L}} \\
\left(\mathrm{L} \mathrm{mg}^{-1}\right)\end{array}$ & $\mathrm{R}^{2}$ & $\mathrm{~K}_{\mathrm{F}}$ & $1 / \mathrm{n}$ & $\mathrm{R}^{2}$ \\
$298 \mathrm{~K}$ & -35.82 & -0.044 & -0.27359 & 1.42 & 1.457 & 0.52557 \\
$318 \mathrm{~K}$ & -8.88 & -0.46 & 0.63996 & 10.34 & 2.211 & 0.93649 \\
$328 \mathrm{~K}$ & -22.22 & -0.50 & -0.06776 & 35.90 & 2.005 & 0.38741 \\
\hline
\end{tabular}

\section{References}

Alver, E., and A. ü Metin. 2012. Anionic Dye Removal from Aqueous Solutions Using Modified Zeolite: Adsorption Kinetics and Isotherm Studies. Chemical Engineering Journal 200-202: 59-67.
Amarasinghe, B.M.W.P.K., and R.A. Williams. 2007. Tea Waste as a Low Cost Adsorbent for the Removal of $\mathrm{Cu}$ and $\mathrm{Pb}$ from Wastewater. Chemical Engineering Journal 132 (1-3): 299309. 
AOAC 2010. Association of Official Analytical Chemists. Official methods of analysis, $15^{\text {th }}$ edition, Washington D.C. USA, 910-928

Azizian, S. 2006. A Novel and Simple Method for Finding the Heterogeneity of Adsorbents on the Basis of Adsorption Kinetic Data. Journal of Colloid and Interface Science 302 (1): 76-81.

Babalola, J.O., B.A. Koiki, Y. Eniayewu, A. Salimonu, J.O. Olowoyo, V.O. Oninla, H.A. Alabi, A.E. Ofomaja, and M.O. Omorogie. 2016. Adsorption Efficacy of Cedrela Odorata Seed Waste for Dyes: Non Linear Fractal Kinetics and Non Linear Equilibrium Studies. Journal of Environmental Chemical Engineering 4 (3): 3527-3536.

Banat, I.M., P. Nigam, D. Singh, and R. Marchant. 1997. Erratum: Microbial Decolorization of Textile-Dye-Containing Effluents: A Review Bioresource Technology 58: 217-227.

Bello, O.S., M.A. Ahmad, and B. Semire. 2015. Scavenging Malachite Green Dye from Aqueous Solutions Using Pomelo (Citrus Grandis) Peels: Kinetic, Equilibrium and Thermodynamic Studies. Desalination and Water Treatment 56 (2): 521-535.

Blackburn, R.S. 2004. Natural Polysaccharides and Their Interactions with Dye Molecules: Applications in Effluent Treatment. In Environmental Science and Technology 38: 4905-4909.

Crini, G. 2006. Non-Conventional Low-Cost Adsorbents for Dye Removal: A Review. Bioresource Technology 97 (9): 1061-1085.

Garg, V.K., R. Gupta, A.B. Yadav, and R. Kumar. 2003. Dye Removal from Aqueous Solution by Adsorption on Treated Sawdust. Bioresource Technology 89 (2): 121-124.

Ho, Y. 2006. Second-Order Kinetic Model for the Sorption of Cadmium onto Tree Fern: A Comparison of Linear and Non-Linear Methods. Water Research 40: 119- 125.
Kannan, N., and M.M. Sundaram. 2001. Kinetics and Mechanism of Removal of Methylene Blue by Adsorption on Various Carbons - A Comparative Study. Dyes and Pigments 51 (1): 25-40.

Kaushik, P., and A. Malik. 2009. Fungal Dye Decolourization: Recent Advances and Future Potential. Environment International 35 (1): 127-141.

Maas, R., and S. Chaudhari. 2005. Adsorption and Biological Decolourization of Azo Dye Reactive Red 2 in Semicontinuous Anaerobic Reactors. Process Biochemistry 40 (2): 699-705. Nandi, S., C.K. Roy, M. Asad, and A.K. Das. 2009. Effect of Betel Quid on Chemically Induced Hepatic Damage. Pharmacologyonline 1: 826-844.

Ofomaja, A.E., and E.B. Naidoo. 2011. Biosorption of Copper from Aqueous Solution by Chemically Activated Pine Cone: A Kinetic Study. Chemical Engineering Journal 175 (1): 260-270.

Ojedokun, A.T., and O.S. Bello. 2016. Sequestering Heavy Metals from Wastewater Using Cow Dung. Water Resources and Industry 13: 7-13.

Omorogie, M.O., J.O. Babalola, E.I. Unuabonah, and J.R. Gong. 2012. Kinetics and Thermodynamics of Heavy Metal Ions Sequestration onto Novel Nauclea Diderrichii Seed Biomass. Bioresource Technology 118 (December 2013): 576-579.

Onal, I., S. Soyer, and S. Senkan. 2006. Adsorption of Water and Ammonia on TiO2Anatase Cluster Models. Surface Science 600 (12): 2457-2469.

Ozcan, A.S., A. Ozcan, S. Tunali, T. Akar, I. Kiran, and T. Gedikbey. 2007. Adsorption Potential of $\mathrm{Pb}$ (II) Ions from Aqueous Solutions onto Capsicum Annuum Seeds. Separation Science and Technology 42: 137-151. 
Pounds, A. 2001. Physical Chemistry for the Chemical and Biological Sciences. Journal of Chemical Education 78 (5): 594.

Repo, E. 2011. EDTA- and DTPAFunctionalized Silica Gel and Chitosan Adsorbents for the Removal of Heavy Metals from Aqueous Solutions. Lappeenranta University of Technology.

Robinson, T., G. McMullan, R. Marchant, and P. Nigam. 2001. Remediation of Dyes in Textile Effluent: A Critical Review on Current Treatment Technologies with a Proposed Alternative. Bioresource Technology 77 (3): 247-255.

Senthilkumar, R., K. Vijayaraghavan, M. Thilakavathi, P.V.R. Iyer, and M. Velan. 2006. Seaweeds for the Remediation of Wastewaters Contaminated with Zinc (II) Ions. Journal of Hazardous Materials 136 (3): 791-799.
Stumm, W., and J.J. Morgan. 1996. Aquatic Chemistry: Chemical Equilibria and Rates in Natural Waters. Environmental Science and Technology. A Wiley Interscience publication.

Tran, H.N., S.J. You, A. Hosseini-Bandegharaei, and H.P. Chao. 2017. Mistakes and Inconsistencies Regarding Adsorption of Contaminants from Aqueous Solutions: A Critical Review. Water Research 120: 88-116.

Willis, J.R. 2009. Exact Effective Relations for Dynamics of a Laminated Body. Mechanics of Materials 41 (4): 385-393.

Zenasni, O., A.C. Jamison, and T.R. Lee. 2013. The Impact of Fluorination on the Structure and Properties of Self-Assembled Monolayer Films. Soft Matter 9 (28): 6356-6370. 